Quim. Nova, Vol. 36, No. 6, 848-858, 2013

\title{
BIOSSURFACTANTES: PROPRIEDADES ANTICORROSIVAS, ANTIBIOFILMES E ANTIMICROBIANAS
}

\author{
Lívia Vieira de Araujo* e Denise Maria Guimarães Freire \\ Departamento de Bioquímica, Instituto de Química, Universidade Federal do Rio de Janeiro, 21941-909 Rio de Janeiro - RJ, Brasil \\ Márcia Nitschke \\ Departamento de Físico-Química, Instituto de Química de São Carlos, Universidade de São Paulo, CP 780, 13560-970 São Carlos \\ - SP, Brasil
}

Recebido em 13/11/12; aceito em 15/2/13; publicado na web em 15/4/13

\begin{abstract}
BIOSURFACTANTS: ANTICORROSIVE, ANTIBIOFILM AND ANTIMICROBIAL PROPERTIES. Due to the importance of biofilms in the food industry, new products are being developed to enhance the efficiency of cleaning food-contact surfaces. Biosurfactants could be an alternative to synthetic products. The major advantages of biosurfactants over synthetic detergents are their low toxicity and highly biodegradable nature. Biosurfactants may also exhibit antimicrobial, anti-adhesive and anticorrosive activity concomitantly. In this review, we emphasize the potential application of biosurfactants as surface coating agents to prevent corrosion and decrease planktonic and sessile microbial growth.
\end{abstract}

Keywords: biosurfactant; antibiofilm; anticorrosive.

\section{INTRODUÇÃO}

Qualquer processo industrial que utilize matéria prima de origem biológica pode fornecer os ingredientes e as condições para o crescimento de micro-organismos, tanto sob a forma planctônica na água circulante quanto como biofilmes sobre superfícies. ${ }^{1}$ Geralmente, a sanitização de superfícies é o método utilizado para prevenir contaminação, no entanto, existem algumas evidências de que as práticas de sanitização atualmente aplicadas são menos efetivas sobre micro-organismos aderidos do que sobre células planctônicas. ${ }^{2}$ Devido à importância dos biofilmes em indústrias alimentícias, novos produtos são constantemente desenvolvidos para melhorar a eficiência de limpeza das superfícies que entram em contato com o alimento durante o processamento. Os biossurfactantes são compostos com propriedades tensoativas, produzidos por micro-organismos. Seu uso foi sugerido como uma alternativa à produtos de origem sintética. As principais vantagens em relação aos detergentes sintéticos residem em sua baixa toxicidade e natureza altamente biodegradável. Desta forma, são menos poluentes que os sintéticos. Estes mesmos produtos também podem apresentar atividade antimicrobiana e antiadesiva simultaneamente. ${ }^{3}$ Nesta revisão enfatizamos a importância do controle de biofilmes, o potencial de uso de biossurfactantes e a aplicação dos mesmos como agentes antimicrobianos, antibiofilmes e anticorrosivos em indústrias alimentícias.

\section{Biofilmes}

Inicialmente, imaginava-se que os micro-organismos viviam de maneira planctônica, ou seja, livres, em suspensão. ${ }^{4}$ Mas atualmente sabe-se que, em sua grande maioria, as bactérias são encontradas em comunidades de diferentes graus de complexidade e a existência do tipo de vida planctônica independente parece ser eventual. ${ }^{4,5}$ As comunidades bacterianas que se desenvolvem entre fases, como interfaces sólido-líquido ou ar-líquido, são chamadas de biofilmes. ${ }^{6} \mathrm{Em}$ indústrias de alimentos, a ocorrência de falhas nos procedimentos de higienização faz com que resíduos de alimentos fiquem aderidos aos equipamentos e superfícies. ${ }^{2,7}$ Então, sob determinadas condições, os

*e-mail: araujolv@me.com micro-organismos aderem, interagem com as superfícies e iniciam a multiplicação celular até formar uma massa celular que é capaz de agregar nutrientes, resíduos e outros micro-organismos. ${ }^{2,8} \mathrm{O}$ termo biofilme não inclui somente os micro-organismos, mas também engloba o material extracelular produzido na superfície e qualquer material que esteja dentro da matriz resultante. ${ }^{9-11} \mathrm{O}$ termo biofilme se refere à interação dinâmica entre as populações bacterianas compostas por uma ou mais espécies, caracterizadas por heterogeneidades temporais (desenvolvimento), espaciais (organização espacial), funcionais (variação na atividade metabólica), estrutura hierárquica e estágios evolucionários bem definidos. Em geral, a diferença entre a simples adesão do micro-organismo às superfícies e o biofilme pode ser definida através dos seguintes critérios: o papel da superfície no crescimento da população bacteriana e a existência de comunicação célula-a-célula (quorum sensing) dentro da população. ${ }^{12}$ Enquanto o termo biofilme se refere a um microambiente complexo em uma superfície, existem vários outros termos que se referem à adesão das bactérias às superfícies. Quando células planctônicas se associam a uma superfície, o termo usual é aderência. O termo adsorção também é usado para descrever o evento inicial da célula bacteriana associar-se a uma superfície. A aderência é baseada em forças físico-químicas atrativas entre o micro-organismo e a superfície. Quando o micro-organismo se torna firmemente aderido, geralmente com a ajuda de material extracelular, o termo fixação pode ser aplicado. ${ }^{10}$

\section{Adesão e formação do biofilme}

Quando um fluído contendo micro-organismos e/ou outras substâncias entra em contato com uma superfície, o primeiro evento que ocorre é a adsorção que geralmente é chamado de condicionamento. O pré-tratamento ou condicionamento de superfícies, frequentemente relacionado à composição do fluido, pode ter efeito inibitório ou estimulante da adesão microbiana. ${ }^{10}$ Os biofilmes podem ser formados por populações desenvolvidas a partir de uma única, ou de múltiplas espécies, podendo ser encontrados em uma variedade de superfícies bióticas e/ou abióticas. ${ }^{13} \mathrm{~A}$ adesão bacteriana pode gerar o processo de multiplicação microbiana e formação de biofilme ${ }^{12-14}$ e pode ser afetado por uma série de fatores como a espécie do micro-organismo, as condições de crescimento e a produção de substâncias extracelulares poliméricas (EPS). ${ }^{4,13}$ Os micro-organismos que são responsáveis 
pelo início da adesão na superfície são denominados colonizadores primários. A presença desses colonizadores primários pode permitir que outros também participem do processo de aderência. ${ }^{10} \mathrm{~A}$ adesão da célula bacteriana a uma superfície condicionada é considerada um evento aleatório. As células aderem, multiplicam e acumulam produzindo uma película de junção, na qual pode ocorrer o acúmulo das células. A película de junção também providencia um meio de estabilizar comunidades que estão continuamente sujeitas às forças de cisalhamento. ${ }^{6}$ As espécies que possuem apêndices celulares como fímbrias, cílios e flagelos, podem fazer a aproximação das células ao substrato mais rapidamente e facilitar a aderência da bactéria. ${ }^{13,15}$ Além disso, a hidrofobicidade e a carga da superfície dos micro-organismos podem afetar suas capacidades de aderir às superfícies. ${ }^{13}$ Vários estudos sugerem que a carga e a hidrofobicidade da superfície celular microbiana possuem um papel importante nos estágios iniciais da adesão, por isso foram desenvolvidos métodos que objetivam a determinação das propriedades físico-químicas das superfícies das células microbianas e das superfícies às quais as células aderem. Estes métodos incluem motilidade eletroforética (ME), ${ }^{15}$ aderência bacteriana ao hidrocarboneto (BATH), aderência microbiana a solventes (MATS) ${ }^{16}$ e aderência ao poliestireno. ${ }^{15} \mathrm{~A}$ hidrofobicidade e a carga superficial das bactérias podem diferir entre espécies, sorotipos ou linhagens, e podem sofrer alterações de acordo com variações nas condições de desenvolvimento, estado fisiológico das células, e composição do meio de suspensão. ${ }^{15} \mathrm{~A}$ classificação da hidrofobicidade das células pode ser dividida em: células fortemente hidrofóbicas, quando mais de $55 \%$ das células passam para a fase do hexadecano; moderadamente hidrofóbicas, quando 30-40\% das células passam para a fase do hexadecano; moderadamente hidrofílicas, quando $10-29 \%$ passam para a fase do hexadecano ou fortemente hidrofílicas, quando menos de $10 \%$ das células passam para a fase do hexadecano. ${ }^{15} \mathrm{~A}$ metodologia do MATS foi desenvolvida para facilitar a caracterização das superfícies das células microbianas. É uma análise simples, rápida e quantitativa que foi inspirada no método BATH. ${ }^{16}$ Existem várias teorias sobre a formação dos biofilmes, o processo mais estudado é observado em termos de distância da bactéria em relação à superfície. Em distâncias maiores que $50 \mathrm{~nm}$, somente forças de longo alcance atuam e a ligação é reversível. Conforme a distância de separação se aproxima de $20 \mathrm{~nm}$, tanto forças de longo alcance (força de van der Waals e eletrostática) quanto interações de curto alcance (ligação química e interações hidrofóbicas) estão operando. Esta fase pode ser reversível, mas com o tempo se torna irreversível. Em distâncias menores que $15 \mathrm{~nm}$ forças adicionais entram em ação como a produção de polímeros adesivos que levam à fixação irreversível. A fase final depende da habilidade do micro-organismo metabolizar e produzir exopolissacarídeos (EPS). ${ }^{7,10}$ Poderíamos subdividir a formação de biofilme em 5 etapas:

1 - Fase de Aproximação: Aproximação do micro-organismo à superfície e ligação reversível (Lifshitz-van der Waals e eletrostática), micro-organismos a $50 \mathrm{~nm}$ de distância da superfície, neste ponto a aproximação também é mediada por propriedades não específicas da superfície da célula.

2 - Fase de adesão: Transição da ligação reversível para irreversível, de forma que, devido a repulsão eletrostática (20nm da superfície), começam a ocorrer interações secundárias e o rearranjo das bactérias sobre a superfície remove a água, auxiliando na ocorrência de interações específicas de curta distância.

3 - Fase aderida: Ligação irreversível. Micro-organismos a distâncias menores que $15 \mathrm{~nm}$ da superfície (ligação química e interações hidrofóbicas);

4 - Fase de Maturação do biofilme: Produção de polímeros adesivos e multiplicação celular;

5 - Fase de Biofilme maduro: Início da dispersão de células do biofilme para colonização de outros nichos;
Existem outros princípios gerais que foram referidos como aplicáveis à adesão bacteriana como o da energia livre. ${ }^{10} \mathrm{~A}$ adesão ocorre se resultar em um decréscimo da energia livre do sistema. Com base no balanço da energia livre interfacial é possível calcular se ocorre esse decréscimo de energia livre no sistema e predizer (negligenciando interações de cargas elétricas, uma vez que sistemas biológicos geralmente tem grande força iônica e essas interações geralmente são negligenciáveis) se a adesão será mais favorável ou menos favorável de acordo com cada superfície e micro-organismo. ${ }^{17,18}$ Porém, alguns estudos observaram que nem sempre esse critério é válido. ${ }^{19}$ Interações hidrofóbicas foram sugeridas como responsáveis por uma ampla gama de fenômenos de aderência. Existem evidências para sugerir que a hidrofobicidade pode estar relacionada a estruturas proteicas na superfície da célula. Entretanto, não está claro na literatura que a hidrofobicidade é uma forte precursora da aderência a várias superfícies sólidas. Por outro lado, pode ser um dos fatores envolvidos na aderência inicial dos micro-organismos às superfícies..$^{10,20}$ Quanto maior a hidrofobicidade das superfícies envolvidas na formação do biofilme, maior será a formação deste. ${ }^{21} \mathrm{~A}$ hidrofobicidade bacteriana pode variar muito entre diferentes linhagens de mesmos micro-organismos. ${ }^{22} \mathrm{~A}$ hidrofobicidade da parede celular pode estar relacionada à adesão, tanto em superfícies hidrofóbicas quanto em superfícies hidrofílicas. ${ }^{23}$ Em superfícies hidrofóbicas, as interações hidrofóbicas são consideradas as principais forças e, em superfícies hidrofílicas, as interações eletrostáticas são as principais. Repulsões hidrofílicas e atrações hidrofóbicas são devidas principalmente às interações acidobásicas de Lewis e às interações de Lifshitz-van der Waals geralmente interferem menos. ${ }^{16}$ Bactérias com altos valores de $\mathrm{DG}_{i W i}$ (mais hidrofóbicas) são fortemente doadoras de elétrons e bactérias que possuem baixos valores de $\mathrm{D} G_{i W i}$ (menos hidrofóbicas/ hidrofílicas) são fracamente doadoras de elétrons. ${ }^{24}$ Geralmente, superfícies hidrofóbicas apresentam baixos valores de ambos componentes aceptores de elétrons e doadores de elétrons. ${ }^{25}$ Portanto, estes parâmetros também poderiam ser utilizados na avaliação da adesão microbiana às superfícies. A temperatura e a fase de crescimento podem influenciar sobre a composição da parede celular, tornando-a menos ou mais hidrofóbica, doadora ou aceptora de elétrons. ${ }^{9}$ Todas as características físico-químicas são estritamente relacionadas com a adesão microbiana e a formação de biofilmes, e a alteração de cada parâmetro pode influenciar positiva ou negativamente sobre a adesão microbiana. ${ }^{26} \mathrm{O}$ desenvolvimento microbiano na superfície está associado com agitações massivas, reguladas pela cinética de crescimento celular e a quantidade de nutrientes disponíveis. As células bacterianas enviam sinais para outras. É necessário que se estabeleça um comportamento multicelular, que é refletido por atividades coordenadas de interação e comunicação dos vários micro-organismos. Dentre os mecanismos de comunicação inter-bacteriana, importantes na formação, organização da arquitetura e desenvolvimento dos biofilmes, se destaca o quorum sensing. ${ }^{4,6,12}$

\section{As bases do quorum sensing}

O quorum sensing é um termo usado para descrever o processo de comunicação intra e interespécies microbianas, que permite que estas tenham a capacidade de se comportar como organismos complexos, que se comunicam e agem coordenadamente, respondendo a diferentes estímulos de modo unificado, sendo tal processo mediado pela densidade populacional. Este mecanismo é realizado por meio de moléculas denominadas auto-indutores (AI). Os dois mecanismos mais bem descritos são os sistemas da Acil-homoserina lactona (HSL) de muitos micro-organismos Gram-negativos; e os sistemas sinalizadores baseados em peptídeos de muitos micro-organismos Gram-positivos. Ainda existe um amplo sistema chamado de AI-2 que é encontrado em várias espécies Gram-positivas e Gram-negativas, 
sendo descrito como responsável pela comunicação inter-espécies., ${ }^{4,27}$ Existe grande evidência de que as bactérias possuem sistemas que monitoram e respondem aos sinais de quorum sensing de outras espécies. Em alguns casos, estes sistemas podem ser muito específicos, e em outros pode haver métodos para a percepção dos sinais ou roteiros produzidos por praticamente qualquer membro da microbiota local. ${ }^{27,28}$ Durante o crescimento microbiano, todas as células produzem e liberam uma certa quantidade de AI. Quando a população atinge a fase exponencial (alta densidade populacional) e o início da fase estacionária de crescimento, a quantidade de AI chega a uma concentração limite, suficiente para disparar o processo de alteração da expressão gênica. ${ }^{4}$ Em uma cultura planctônica, é presumível que todas as bactérias estejam fisiologicamente semelhantes, produzindo moléculas sinalizadoras na mesma proporção. No contexto de um biofilme, heterogeneidades na população que acontecem por mutação podem dar espaço a nichos de seus clones dentro do biofilme. ${ }^{27}$ As células planctônicas usam os sinais químicos para regular uma variedade de processos dependentes da densidade populacional. ${ }^{28}$ Mas em várias espécies bacterianas como a Pseudomonas aeruginosa, Burkholderia cepacia, Streptococcus mutans e outras, os mesmos sinais são conhecidos como roteiros para o desenvolvimento dos biofilmes. ${ }^{29}$ Isto foi primeiramente demonstrado com a bactéria $P$. aeruginosa, na qual os sinais de quorum sensing controlam a expressão de centenas de genes. Logo, a formação do biofilme é uma atividade social controlada tanto por fatores genéticos, quanto por fatores ambientais. ${ }^{28}$ Existem evidências que suportam a ideia de que, para algumas espécies bacterianas, o quorum sensing controla a dispersão do biofilme. ${ }^{27}$

\section{Estrutura do biofilme}

Os biofilmes contêm partículas de proteínas, lipídeos, fosfolipídios, carboidratos, sais minerais, vitaminas, entre outros, formando camadas onde os micro-organismos de uma ou mais espécies se desenvolvem. ${ }^{7}$ Eles são representados pela interação e organização de estruturas tridimensionais de organismos envolvidos por EPS, com redes de canais de água, e múltiplas camadas de células. ${ }^{4,6}$ Logo, as estruturas físicas e biológicas dos biofilmes estão sujeitas às múltiplas influências intrínsecas (composição química, microbiota natural) e extrínsecas (ambientais) que vão afetar o crescimento microbiano e consequentemente a composição da comunidade microbiana. ${ }^{1}$ Várias propriedades físicas dos biofilmes podem ser atribuídas à matriz de EPS. ${ }^{6}$ A matriz EPS pode ser de natureza polissacarídica ou proteica e fica exposta nas células Gram-negativas exteriormente à membrana externa das células, e nas células Gram-positivas exteriormente ao peptídeoglicano. ${ }^{7}$ A matriz EPS possibilita as ligações célula-a-célula, assim como faz as ligações de células individuais às superfícies, ${ }^{5}$ além de serem hidratados e servirem como reserva de nutrientes. ${ }^{4,5}$ Sob fluxo turbulento, os biofilmes formados por comunidades complexas espalham-se pelas superfícies, o que é compatível com o comportamento do EPS como um fluído viscoelástico. Essas características fazem com que o biofilme seja considerado uma entidade dinâmica. ${ }^{6} \mathrm{O}$ caráter hidrofílico é predominantemente correlacionado às altas concentrações de polissacarídeos e às baixas concentrações de compostos hidrocarbonados na superfície celular. ${ }^{30}$ Como diversos fatores podem interferir no processo de adesão microbiana à superfície, como apêndices celulares, ${ }^{13,15}$ hidrofobicidade e carga da superfície dos micro-organismos ${ }^{13}$ em relação à hidrofobicidade e carga da superfície à qual vão aderir $^{31}$ e a capacidade ou não de produzir exopolissacarídeos, ${ }^{13}$ as linhagens com maior capacidade de produzir exopolissacarídeos (EPS), provavelmente são as menos hidrofóbicas e possuem maior capacidade de formar biofilmes. Foi verificado que quanto maiores os níveis de carboidratos extracelulares produzidos por diferentes linhagens de L. monocytogenes, maior a capacidade delas de formar biofilmes, destacando a importância desta característica para a habilidade de uma dada linhagem em formar biofilmes. ${ }^{15}$ Outro trabalho também correlacionou a maior produção de exopolissacarídeos com as linhagens de L. monocytogenes capazes de ter maior adesão a superfícies. ${ }^{32}$

\section{Dispersão do biofilme}

Vários fatores afetam a dispersão das células dos biofilmes como temperatura, tempo, forças mecânicas e forças químicas. ${ }^{1}$ Em determinados momentos, os biofilmes liberam micro-organismos que podem colonizar outros ambientes. Existem diferentes processos de dispersão, como a dispersão expansiva, na qual conforme as células de uma micro-colônia se multiplicam, usam o carbono proveniente da película de EPS como fonte de nutriente. Assim, o material polissacarídico se desintegra, facilitando a saída de células que precisam de nutrientes da superfície. Ou quando as células morrem e perdem massa, assim a cápsula de EPS se fragiliza e se fragmenta liberando células da estrutura para o ambiente. Outro processo é o de dispersão por fragmentação do biofilme, em que porções da matriz EPS junto com micro-organismos são liberadas, sendo um dos principais motivos a ação estressante das forças de cisalhamento. E ainda existe a dispersão superficial, que ocorre devido ao crescimento do próprio biofilme como um todo. ${ }^{4,12}$

\section{Principais micro-organismos encontrados em biofilmes na indústria de alimentos}

Nas indústrias de processamento de alimentos, alguns micro-organismos causam danos aos produtos, interferindo na qualidade de estocagem e provocando a deterioração do alimento, o que coloca em risco a segurança alimentar devido à transmissão de doenças a partir deste alimento, principalmente se essa contaminação ocorrer após uma etapa de pasteurização/esterilização do produto. ${ }^{10}$ São vários os micro-organismos encontrados nos processos de adesão na área de alimentos, dentre eles os principais são: P. aeruginosa, Pseudomonas fragi, Pseudomonas fluorescens, Micrococcus sp, Enterococcus faecium, Listeria monocytogenes, Yersinia enterocolitica, Salmonella thyphimurium, Escherichia coli O157:H7, Staphylococcus aureus e Bacillus cereus. ${ }^{1,4,710}$ A L. monocytogenes é uma bactéria muito comum em indústrias de alimentos, devido à sua facilidade de formar biofilmes sobre diversas superfícies como, por exemplo: aço inox, PET, PTFE, PVC, PE, vidro; e devido também à sua capacidade de se desenvolver sob diversas condições como em baixas temperaturas, em $\mathrm{pH}$ ácido e em meio extremamente salino. ${ }^{11,33,34}$ Além disto, produz EPS e com isso se desenvolve nas superfícies onde o alimento entra em contato, neutralizando agentes antimicrobianos e aumentando a resistência à desinfecção. ${ }^{35}$ Sua importância se deve principalmente ao seu potencial patogênico. Dentre os alimentos envolvidos na ocorrência de listeriose destacam-se os produtos lácteos como o leite cru ou pasteurizado, os sorvetes e queijos; os produtos cárneos crus ou termoprocessados de diversas origens como: bovina, ovina, caprina, suína e de aves; os peixes crus ou defumados; e os embutidos preparados a partir de carne crua fermentada, além dos produtos de origem vegetal, marinha e as refeições pré-preparadas. ${ }^{36-38}$ A $P$. fluorescens também possui uma grande capacidade de formação de biofilme. Além disto, pertence a um dos gêneros mais frequentemente encontrados em circuitos de água de sistemas industriais. ${ }^{19}$ Os sistemas de tratamento de água e de filtração de sucos que utilizam membranas geralmente encontram problemas como a bioincrustação ("biofouling”), levando a perdas na performance geral destes processos. A bioincrustação é caracterizada pela adsorção de partículas e micro-organismos à superfície, iniciando o desenvolvimento de biofilmes. Neste caso, mesmo micro-organismos não-patogênicos como a $P$. fluorescens trazem grandes prejuízos, pois vão sobrecarregar o sistema, aumentando 
a pressão de trabalho, podendo levar a entupimento, rompimento das membranas e gastos desnecessários com energia e paralização dos trabalhos. ${ }^{39}$ A $P$. fluorescens é capaz de formar biofilmes com facilidade sobre uma ampla gama de superfícies, incluindo o poliestireno, a poliamida e o aço inox..$^{19,40}$

\section{Resistência dos biofilmes}

Nos biofilmes, os micro-organismos são mais resistentes do que as células de vida livre à ação de agentes químicos e físicos, como os que são usados nos procedimentos de higienização. ${ }^{20}$ Esta resistência das células do biofilme às influências externas como antibióticos, defesas do hospedeiro, antissépticos e forças de cisalhamento, é uma preocupação constante nas indústrias e na medicina. ${ }^{6}$ Existem três mecanismos usualmente aceitos que justificam a resistência maior dos micro-organismos presentes nos biofilmes, são eles: a capacidade do EPS impedir o contato do agente com os micro-organismos, funcionando como um filtro; os micro-organismos apresentarem um estado metabólico diferenciado (metabolismo mais lento) e a capacidade de modificar e/ou neutralizar o agente (principalmente em biofilmes com mais de uma espécie). Logo, o EPS não providencia necessariamente uma barreira de difusão contra compostos inibitórios (antimicrobianos), mas as bactérias do biofilme podem ser inerentemente mais resistentes. Em biofilmes com várias espécies, as espécies podem se beneficiar entre si por meio da troca de substrato e/ou remoção mútua de metabólitos. Este nível de estrutura organizacional e especialização metabólica justifica a marcante eficiência metabólica dos biofilmes e sua resistência inerente a agentes antimicrobianos. A matriz também pode proteger os micro-organismos dos efeitos do vapor. ${ }^{1,6}$

\section{Métodos de avaliação e quantificação da adesão a superfícies}

Os métodos de avaliação de biofilmes podem ser visuais ou diretos, como a remoção das células (raspagem, ultrassom, vortex ou agitação com pérolas de vidro) seguida de contagem por métodos tradicionais (contagem padrão em placa); a microscopia de contraste de fase, que é usada para acompanhar em tempo real o desenvolvimento do biofilme em uma superfície transparente; a microscopia de epifluorescência, que é excelente para a quantificação das células aderidas às superfícies; a microscopia eletrônica de varredura (MEV) e a de transmissão (MET) que são as mais indicadas para a avaliação da interação microbiana na matriz do biofilme..$^{1,5,7,10,13}$ Os métodos de remoção das células das superfícies, seguidos por contagem de células viáveis, podem ser inconsistentes devido à dificuldade da completa remoção das células fixadas. Em pesquisas nas quais biofilmes estão sendo estudados, pode ser fácil remover uma alta porcentagem das células aderidas da superfície pela raspagem ou agitação forte com pérolas de vidro. ${ }^{5,10,20}$ Muitos estudos vêm realizando com sucesso a quantificação indireta de biofilmes corando-os com cristal violeta e lendo a absorbância após ressolubilização do corante, ${ }^{41-45}$ esta mesma metodologia é utilizada para classificar os micro-organismos em: não aderentes; fracamente aderentes; moderadamente aderentes; $\mathrm{e}$ fortemente aderentes. ${ }^{41}$ Apesar da morfologia dos biofilmes sofrer algumas alterações durante processos de desidratação, é possível conseguir boa informação pela utilização da MEV para comparar e demonstrar claramente diferenças na estrutura de biofilmes submetidos a diferentes condições. ${ }^{46} \mathrm{O}$ microscópio eletrônico de varredura ambiental (MEVA) é uma excelente opção pois permite o trabalho sem a necessidade de um preparo prévio à visualização. Uma variedade de provas fluorescentes pode ser utilizada na análise in situ da arquitetura populacional de biofilmes.

\section{Biofilmes no processamento de alimentos}

O principal objetivo do processamento de alimentos é conseguir meios de fornecer alimentos seguros, com qualidade nutricional e sensorial aos consumidores. O controle dos micro-organismos é essencial para se alcançar essa meta. ${ }^{2,10}$ A regulamentação das indústrias alimentícias exige nível de tolerância zero para patógenos como Salmonella spp. e L. monocytogenes, pois uma única célula pode ser tão importante como um biofilme já desenvolvido, ${ }^{10}$ devido a seus potenciais patogênicos. As bactérias podem aderir a uma variedade de superfícies encontradas nos ambientes de processamento de alimentos. Para reduzir ou eliminar os micro-organismos das superfícies em que o alimento vai entrar em contato, os processadores de alimentos utilizam técnicas que incluem métodos físicos, como a lavagem manual e "sprays" de alta pressão, assim como métodos químicos como o uso de hipocloritos, iodóforos e compostos de amônia quaternária. Ambas as técnicas removem e inativam os micro-organismos que podem estar presentes na superfície do equipamento e que poderiam eventualmente entrar em contato com alimentos crus ou processados. ${ }^{10} \mathrm{~A}$ fixação bacteriana e a subsequente formação de biofilme em uma ampla gama de superfícies comumente utilizadas no processamento de alimentos pode ocorrer em tempos de contato tão curtos como 20 minutos, dependendo do micro-organismo e das condições ambientais. ${ }^{5}$ Processos industriais que lidam com qualquer material biológico fornecem ingredientes e condições de crescimento para micro-organismos. ${ }^{1}$ Células viáveis de um biofilme são perigos em potencial, pois se forem transferidas para o alimento, podem gerar um grande impacto negativo. ${ }^{10} \mathrm{~A}$ sanitização das superfícies com as quais alimentos vão entrar em contato é uma forma de prevenir a contaminação. Infelizmente existem evidências de que as práticas de sanitização atuais são menos efetivas em micro-organismos aderidos do que em micro-organismos de vida livre., ${ }^{2,5}$ Na maioria das plantas processadoras de alimentos, a sanitização é precedida pela limpeza com detergentes, pois se sabe que a eficácia do agente sanificante é reduzida pela presença de matéria orgânica. As recomendações de limpeza e sanitização ainda são as melhores maneiras de combater a contaminação. Além disso, os detergentes podem ser considerados como o componente de maior importância no controle do número bacteriano, devido à sua capacidade de remover a matéria orgânica da superfície que serviria como substrato para a adesão microbiana. ${ }^{10,47}$ Mesmo com a utilização de sistemas reconhecidos de limpeza, as bactérias podem permanecer nas superfícies dos equipamentos e sobreviver por períodos prolongados, dependendo da quantidade e natureza do substrato residual, da temperatura e da umidade relativa. ${ }^{1}$ Existe uma grande variedade de superfícies que entra em contato com os alimentos e que pode promover o processo de aderência microbiana como o aço inox, vidro, ferro fundido, borracha, polipropileno, poliestireno, polietileno de baixa-densidade e policarbonato. Por isso a escolha dos materiais das superfícies é importante no combate à formação de biofilmes. Deve-se escolher o material que seja mais resistente à limpeza mecânica e a agentes químicos. As áreas mais propícias ao desenvolvimento de biofilmes na linha de processamento são os espaços mortos, juntas, válvulas, vedações e superfícies corroídas pelo tempo de uso. ${ }^{1,13,48} \mathrm{O}$ poliestireno (PE) é um material extensamente utilizado para diversas aplicações. As principais são: embalagens e descartáveis (38\%), refrigeração (16\%), eletrodomésticos $(5 \%)$ e outros $(42 \%){ }^{49}$ No setor alimentício, geralmente é aplicado em potes (embalagens) para iogurte, cremes, sobremesas, leite e bebidas lácteas, cream cheese, queijo cottage, entre outros; podem estar presentes em pratos descartáveis contendo frutas, refeições prontas, carne fresca, entre outros; também estão presentes em bandejas utilizadas para produtos agrícolas como exemplo para ovos e para coletar e separar as vísceras na hora do abate, também em bandejas de redes de fast-food, em produtos de confeitaria e padaria, em tampas de bebidas em frascos de ervas e especiarias, sopas instantâneas etc. ${ }^{50}$ Ademais, os biofilmes também podem causar perdas de energia e bloqueios em tubos condensadores, materiais resfriadores, circuitos de água e de esgoto, 
e em trocadores térmicos. ${ }^{1}$ Novas formas de controle de formação de biofilmes são constantemente pesquisadas, dentre elas, o controle através de fatores ambientais na linha de processamento e o uso de agentes tensoativos, dispersantes, biodispersantes, enzimas, e novos compostos químicos biocidas, em adição a compostos químicos não tóxicos ou minimamente tóxicos. Assim como a limpeza das superfícies, o treinamento dos funcionários, boas práticas de fabricação e boa estrutura de processamento são fatores importantes no combate aos problemas higiênicos da indústria alimentícia. ${ }^{1}$

\section{Biossurfactantes}

Os surfactantes constituem uma classe importante de compostos químicos amplamente utilizados em diversos setores industriais, principalmente como matéria-prima na fabricação de detergentes de uso doméstico. ${ }^{51} \mathrm{~A}$ maioria dos surfactantes disponível comercialmente é sintetizada a partir de derivados do petróleo ${ }^{51,52}$ e foi somente nas últimas décadas que as moléculas de origem biológica com propriedades tensoativas foram descritas. ${ }^{53}$ Vários compostos com propriedades tensoativas são sintetizados por organismos vivos, desde plantas (saponinas) até micro-organismos (glicolipídios) e também no organismo humano (sais biliares), sendo considerados surfactantes naturais. ${ }^{54}$ Os compostos de origem microbiana que exibem propriedades surfactantes, isto é, diminuem a tensão superficial e possuem alta capacidade emulsificante, são denominados biossurfactantes e consistem em subprodutos metabólicos de bactérias, fungos filamentosos e leveduras. ${ }^{55}$ Os micro-organismos produtores distribuem-se em diversos gêneros, sendo a maioria deles bactérias. ${ }^{51}$ Os surfactantes convencionais são usados para uma ampla gama de propósitos em uma grande variedade de aplicações. A maioria dos requisitos para um surfactante convencional poderia ser preenchida pelo biossurfactante. Para justificar a troca de um surfactante sintético por um composto biológico é necessário encontrar um agente mais efetivo para uma dada aplicação e/ou um que possa ser produzido com custos mais baixos. ${ }^{56-58}$ Os surfactantes são moléculas anfipáticas que tem tanto porções hidrofílicas quanto porções hidrofóbicas. A porção apolar é frequentemente uma cadeia de hidrocarbonetos ${ }^{56}$ enquanto que a porção polar pode ser iônica (aniônica ou catiônica), não-iônica ou anfotérica. ${ }^{54} \mathrm{O}$ equilíbrio entre a parte hidrofílica e hidrofóbica na mesma molécula proporciona propriedades não usuais, incluindo a habilidade de diminuir a tensão superficial da água. ${ }^{52,56}$ Estas propriedades únicas fazem os surfactantes serem adequados para uma ampla gama de aplicações industriais que envolvem detergência, emulsificação, lubrificação, capacidade de formar espuma, capacidade molhante, solubilização e dispersão de fases. ${ }^{52,54,59}$

\section{Estruturas}

Os biossurfactantes constituem uma das principais classes de surfactantes naturais, sendo classificados de acordo com a sua composição química e sua origem microbiana, diferentemente dos surfactantes sintetizados quimicamente que são classificados de acordo com seus grupos polares. As principais classes incluem glicolipídios, lipopeptídeos e lipoproteínas, fosfolipídios e ácidos graxos, surfactantes poliméricos e surfactantes particulados. ${ }^{52} \mathrm{~A}$ porção lipofílica é quase sempre composta por cadeia hidrocarbônica de um ou mais ácidos graxos, que podem ser saturados, insaturados, hidroxilados ou ramificados. A parte solúvel em água (polar) de um biossurfactante pode ser tão simples como um carboxilato, um grupo hidróxi ou uma mistura complexa como fosfato, carboidrato, aminoácidos, etc. ${ }^{52} \mathrm{~A}$ maioria dos biossurfactantes é neutra ou carregada negativamente variando de pequenos ácidos graxos até grandes polímeros. Nos biossurfactantes aniônicos, a carga é devido a um carboxilato e/ou fosfato ou, ocasionalmente, a um grupo sulfato. Um pequeno grupo de biossurfactantes catiônicos contém grupamentos amino. ${ }^{54}$

\section{Função fisiológica dos biossurfactantes}

Os biossurfactantes são produzidos por uma variedade de micro-organismos, predominantemente durante o crescimento em substratos insolúveis em água, sendo secretados extracelularmente ou ligados a partes de células. Do ponto de vista fisiológico, a produção desta quantidade abundante de moléculas tensoativas representaria um alto custo metabólico caso não houvesse uma função específica, e provavelmente os genes responsáveis pela produção não seriam conservados nos genomas destes micro-organismos. ${ }^{52}$ Embora a exata função fisiológica dos biossurfactantes ainda não tenha sido completamente elucidada, algumas funções têm sido atribuídas a eles, como a emulsificação e a solubilização de hidrocarbonetos ou compostos insolúveis em água, facilitando o crescimento de micro-organismos nestes substratos; transporte de hidrocarbonetos; regulação da aderência-liberação da célula a superfícies; atividade antibiótica que é demonstrada por vários biossurfactantes, principalmente da classe dos lipopeptídeos e glicolipídios, como os ramnolipídios de $P$. aeruginosa e a surfactina de $B$. subtilis que solubilizam os principais componentes das membranas celulares microbianas, adquirindo maior chance de sobrevivência e maior competitividade na busca por nutrientes. ${ }^{52-54}$

\section{Aplicações industriais}

Existem muitas áreas de aplicação onde os surfactantes químicos poderiam ser substituídos pelos biossurfactantes, dentre as quais campos tão diversos como a agricultura, construção, indústrias de bebidas e alimentícias, limpeza industrial, biorremediação de poluentes insolúveis em água, lubrificantes, tratamento do couro, indústrias de papel e metal, indústrias têxteis, cosméticos, indústria farmacêutica, e indústrias de petroquímicos e petróleo..$^{52,53,55,56} \mathrm{Na}$ indústria de alimentos, os biossurfactantes apresentam propriedades úteis como emulsificantes, ${ }^{55}$ agentes antiadesivos e antimicrobianos. ${ }^{60}$ Devido às suas propriedades funcionais, os emulsificantes são parte indispensável de produtos alimentícios que exigem superioridade sensorial, estabilidade e maior vida de prateleira. ${ }^{61} \mathrm{~A}$ emulsificação tem papel importante na formação da consistência e textura, bem como na dispersão de fase e na solubilização de aromas. Os biossurfactantes podem ser utilizados como emulsionantes no processamento de matérias-primas alimentícias. Os agentes tensoativos encontram aplicação em panificação, produtos derivados da carne $^{54}$ e do leite (queijos cremosos e sorvetes), dos quais a adição de emulsificantes melhora a textura e a cremosidade, ${ }^{61}$ influenciando as características reológicas da farinha e a emulsificação de gorduras. Estas qualidades são de grande valia para produtos contendo baixo teor de gordura. ${ }^{62} \mathrm{Um}$ exemplo é o uso do bioemulsificante produzido por Candida utilis em molhos prontos para saladas. ${ }^{52,53}$ O liposan foi utilizado com sucesso para emulsificar óleos comestíveis. ${ }^{61} \mathrm{~A}$ atividade antimicrobiana também pode ser explorada por meio do uso de biossurfactantes. A combinação de nisina com ramnolipídios foi capaz de aumentar a vida de prateleira e inibir esporos termofílicos em leite de soja UHT. O uso de natamicina associada a ramnolipídios em molhos para saladas foi capaz de aumentar a vida de prateleira e inibir crescimento de leveduras. A associação de natamicina, nisina e ramnolipídios também prolongou a vida de prateleira e inibiu crescimento de bactérias e leveduras em queijo cottage.$^{61} \mathrm{~A}$ atividade antiadesiva é desejável para evitar a formação de biofilmes em superfícies às quais os alimentos vão entrar em contato. É possível reduzir a adesão de patógenos em superfícies comumente utilizadas em indústrias alimentícias a partir do condicionamento das mesmas com biossurfactantes. ${ }^{63-65} \mathrm{Um}$ biossurfactante produzido por uma linhagem termofílica láctea de 
Streptococcus sp. pode ser usado para o controle de contaminação nas placas de troca de calor dos pasteurizadores, já que ele retarda a colonização do $S$. termophilus responsável pela contaminação. ${ }^{55}$ Os biossurfactantes podem ser candidatos em potencial na busca de produtos com diferentes funcionalidades, desde que eles atinjam os requerimentos de aditivos alimentícios funcionais. ${ }^{54}$ Logo, com todas estas propriedades, estes compostos de origem microbiana poderiam ser utilizados para melhorar a aparência/estabilidade de determinados alimentos; evitar contaminação do alimento diretamente, como um aditivo alimentar (através do uso de formulações adequadas), ou indiretamente, como formulações detergentes para limpeza das superfícies que entram em contato com o alimento. ${ }^{61}$

\section{Vantagens e desvantagens do uso dos biossurfactantes em relação} aos surfactantes convencionais

A demanda industrial por surfactantes é alta, com o aumento da preocupação ambiental entre os consumidores, juntamente com as legislações de controle do meio ambiente, os biossurfactantes vêm surgindo como uma alternativa aos produtos sintéticos existentes. ${ }^{51,54}$ Além disso, existe uma tendência movida pela necessidade de substituição de compostos não biodegradáveis ou pouco biodegradáveis e pelo aumento do requerimento de especificidade dos produtos ${ }^{52}$ tanto para uma atuação mais seletiva quanto para uma atuação mais efetiva. Por enquanto, os biossurfactantes ainda não são competitivos do ponto de vista econômico, comparativamente aos compostos sintetizados quimicamente que estão disponíveis no mercado. As principais razões para este fato estão relacionadas aos altos custos de produção devido à metodologia de bioprocessamento ineficiente, à baixa produtividade das linhagens e à necessidade de uso de substratos caros. ${ }^{53}$ Contudo, esta área tem sido objeto de intensa pesquisa, o que poderá culminar em avanços significativos, tornando estes bioprodutos economicamente competitivos. Os biossurfactantes podem ser sintetizados utilizando procedimentos e substratos relativamente simples e com menor custo, como exemplo, a partir de substratos renováveis. ${ }^{55}$ Inevitavelmente, as fontes de petróleo estão diminuindo e, em algum tempo no futuro, a única fonte de surfactantes será de reservas renováveis. Ainda mais, surfactantes sintéticos usualmente requisitam produtos químicos puros, ou pelo menos classes de substâncias químicas para produzir o produto desejável. Este fato não é crucial para um bioprocesso, visto que é possível produzir biossurfactantes por meio de um processo fermentativo utilizando como fonte de carbono resíduos contendo carboidratos, ácidos graxos ou compostos similares. ${ }^{3,52}$ Portanto, este problema econômico pode ser significativamente reduzido utilizando-se fontes alternativas de nutrientes facilmente disponíveis e de baixo custo como os subprodutos agrícolas ou de processamento industrial, contribuindo para a redução da poluição ambiental e permitindo a valorização econômica dos resíduos que seriam simplesmente descartados. ${ }^{51,54}$ A dificuldade na seleção de um resíduo está em encontrar a composição adequada de nutrientes que permita o crescimento celular e o acúmulo do produto de interesse, além da padronização do substrato devido às variações naturais de composição, bem como os custos de transporte, armazenagem e tratamento prévio necessários. O Brasil é um país essencialmente agrícola, portanto, a quantidade e a facilidade de acesso aos subprodutos agroindustriais são bastante significativas. ${ }^{51}$ Os biossurfactantes são mais eficientes e efetivos com relação à atividade superficial e interfacial do que os surfactantes convencionais (detergentes aniônicos sulfatados), pois produzem menor tensão superficial com menores concentrações de produto ativo. ${ }^{51,54}$ Como exemplo temos o dodecil-sulfato de sódio (SDS) que usualmente apresenta CMC em torno de 2023-2890 mg/L e redução da tensão superficial de $72 \mathrm{mN} / \mathrm{m}$ para $37 \mathrm{mN} / \mathrm{m},{ }^{66}$ enquanto alguns biossurfactantes apresentam valores tensão superficial em torno de $26-29 \mathrm{mN} / \mathrm{m}$ e de CMC 50-200 mg/L. Alguns biossurfactantes apresentam elevada estabilidade térmica, de $\mathrm{pH}$ e força iônica, podendo ser utilizados em ambientes com condições mais drásticas do que as suportadas pelos surfactantes convencionais. Como exemplo, tem-se que a maioria dos biossurfactantes suporta concentrações de $10 \%$ de $\mathrm{NaCl}$ enquanto que uma concentração de 2-3\% é suficiente para inativar os surfactantes convencionais. ${ }^{51,52,54}$ Diferentemente dos surfactantes químicos, os biossurfactantes são prontamente biodegradáveis na água e no solo, apresentando uma melhor compatibilidade ambiental, o que os torna adequados para aplicações como biorremediação e tratamento de resíduos. ${ }^{51,52,54}$ Os biossurfactantes possuem baixa toxicidade, por isso são atrativos, já que os produtos artificiais tem sido motivo de preocupação da população devido aos seus efeitos alérgicos. Além disso, essa baixa toxicidade permite o uso em alimentos, cosméticos e produtos farmacêuticos. ${ }^{3,52}$ Outras vantagens são a possibilidade de serem sintetizados a partir de substratos renováveis e possuírem grande diversidade química, possibilitando aplicações específicas para cada caso particular, ${ }^{51,52,54}$ se mostrando eficientemente comparáveis ou superiores aos surfactantes sintéti$\cos ;{ }^{54}$ não são derivados do petróleo, fator de importância à medida que os preços do petróleo aumentam; além da possibilidade de modificação da estrutura química e das propriedades físicas através de manipulação genética ou bioquímica para o desenvolvimento de produtos para necessidades especificas. ${ }^{51,54}$

\section{Glicolipídicos}

Os ramnolipídios são os glicolipídios mais bem estudados. A maioria das espécies de ramnolipídios se apresenta aniônica quando em solução, ${ }^{67}$ possuem uma ou duas moléculas de ramnose ligadas a uma ou duas moléculas de ácido $\beta$-hidroxidecanóico (ácido caprílico). A primeira descrição da produção dos glicolipídios contendo ramnose foi feita por Jarvis e Johnson (1949). Os principais glicolipídios produzidos por $P$. aeruginosa são o L-ramnosil-Lramnosil- $\beta$-hidroxidecanoil- $\beta$-hidroxidecanoato e o L-ramnosil$\beta$-hidroxidecanoil- $\beta$-hidroxidecanoato, mas também foram relatados outros tipos de ramnolipídios, um ácido- $\beta$-hidroxidecanóico com uma ou duas unidades de ramnose, metil éster derivados dos L-ramnosil-L-ramnosil- $\beta$-hidroxidecanoil- $\beta$-hidroxidecanoato e L-ramnosil- $\beta$-hidroxidecanoil- $\beta$-hidroxidecanoato e ramnolipídios com cadeias de ácidos graxos alternativos..$^{52,59} \mathrm{P}$. aeruginosa pode produzir ramnolipídios a partir de vários substratos, incluindo alcanos $\mathrm{C} 11$ e C12, succinato, piruvato, citrato, frutose, glicerol, óleo de oliva, glicose e manitol. A composição e o rendimento dependem do tipo de biorreator, do modo de condução do bioprocesso, do pH, da composição nutricional, do substrato e da temperatura usada. ${ }^{59}$ O Laboratório de Biotecnologia Microbiana (LaBiM) da UFRJ em convênio com o CENPES/Petrobrás vem desenvolvendo, desde 2000, diversos trabalhos de produção de ramnolipídios utilizando uma linhagem de $P$. aeruginosa PA1, oriunda da coleção de culturas do CENPES/Petrobrás que foi isolada de poços de Petróleo (Sergipe/ BR). A otimização do meio de cultivo, busca de fontes de carbono de baixo custo e modificações no modo de condução do processo fermentativo levaram à minimização $(900 \%)$ da produção de fatores de virulência de natureza proteica, com concomitante aumento da produção de ramnolipídio de 1,2 g/L para cerca de 13,0 g/L. ${ }^{68-70}$

$\mathrm{O}$ mesmo grupo desenvolveu trabalhos de escalonamento da produção deste biossurfactante, contornando o problema de formação de espuma, em biorreatores acoplados a membranas oxigenados de modo não dispersivo. $\mathrm{O}$ processo conduzido em batelada alimentada de glicerol/nitrato em altas relações $\mathrm{C} / \mathrm{N}$ conduziu a um aumento de produtividade volumétrica e da produção de ramnolipídio, e foi escalonado para biorreatores piloto de 200 L. ${ }^{71,72}$ Os ramnolipídios 
produzidos por $P$. aeruginosa PA1 em meio contendo $3 \%$ glicerol e 1,45 g/L de nitrato de sódio, como fontes de carbono e nitrogênio, respectivamente, demonstraram serem capazes de diminuir a tensão superficial para $26,9 \mathrm{mN} / \mathrm{m}^{69}$ e o tipo de ramnolipídio predominante no produto é o $\mathrm{Rha}_{2} \mathrm{C}_{10} \mathrm{C}_{10}$, seguido pelo $\mathrm{RhaC}_{10} \mathrm{C}_{10}{ }^{73}$ Os ramnolipídios também emulsificam alcanos, estimulam o crescimento de $P$. aeruginosa em hexadecano ${ }^{52}$ e apresentam excelentes resultados na lavagem de solos impactados com petróleo. ${ }^{74}$ Vários micro-organismos podem ser produtores de biossurfactantes glicolipídicos. Portanto, a procura de novas moléculas e de micro-organismos que sejam produtores e não patogênicos, de forma a facilitar a aprovação para aplicação em indústrias alimentícias, é um desafio a ser alcançado. A espécie de Burkholderia kururiensis KP23 se enquadra no quesito não-patogenicidade e foi identificada como produtora de moléculas glicolipídicas, que foram recentemente caracterizadas pelo Laboratório de Microbiologia Microbiana em conjunto com o Laboratório de Microbiologia Molecular e Proteínas. ${ }^{75}$ Esta cepa foi inicialmente isolada em um lago contaminado com tricloroetileno em Kururi na prefeitura de Chiba, no Japão. ${ }^{76}$

\section{Lipopeptídicos}

O lipopeptídeo surfactante mais bem estudado é o produzido por Bacillus subtilis e recebeu o nome usual de surfactina, sendo conhecido como um dos biossurfactantes mais potentes. ${ }^{53}$ É um biossurfactante aniônico, ${ }^{55}$ possui a capacidade de reduzir a tensão superficial de 72 para $27,9 \mathrm{mN} / \mathrm{m}$ em concentrações tão baixas quanto 0,005\%. Sete aminoácidos (Glu - Leu - Leu - Val - Asp - Leu - Leu) neste composto formam um anel e a porção lipídica é composta por um ácido graxo beta-hidroxilado contendo de 13 a 15 carbonos. Outra característica deste composto é a sua capacidade de lisar eritrócitos de mamíferos e formar esferoblastos; esta propriedade é usada para detectar a produção de surfactina por meio da hemólise no ágar sangue. ${ }^{52,53,59,77}$ A estrutura primária da surfactina foi determinada em 1969 por Kanikuma e colaboradores. Mais recentemente, em 1995, a estrutura tridimensional foi determinada por Bonmatin e colaboradores a partir de técnicas de ressonância magnética nuclear. ${ }^{59}$ A surfactina produzida a partir de um isolado de B. subtilis LB5a, utilizando manipueira como substrato alternativo, foi capaz de apresentar valores de tensão superficial de $26,9 \mathrm{mN} / \mathrm{m}$, tensão interfacial contra o hexadecano de $0,96 \mathrm{mN} / \mathrm{m}$ e concentração micelar crítica (CMC) de $33 \mathrm{mg} / \mathrm{L}$. Este mesmo produto apresentou a isoforma de massa molecular 1036 como predominante, o que representa o lipopeptídeo com sete aminoácidos e quinze carbonos na porção lipídica. ${ }^{78}$ Alguns estudos demonstraram que composição e tamanho das cadeias de ácidos graxos variam de acordo com o meio utilizado e pode resultar em maiores atividades surfactantes específicas. ${ }^{79,80}$ A surfactina possui várias aplicações farmacêuticas como a inibição da formação de coágulos; formação de canais iônicos em membranas; atividade antibacteriana e antifúngica; atividade antiviral e antitumoral. ${ }^{51,54}$ Vários micro-organismos podem ser produtores de biossurfactantes lipopeptídicos. Da mesma forma, a procura de novas moléculas e de micro-organismos que sejam bons produtores e não patogênicos é um desafio a ser alcançado. A espécie de Bacillus sp. $\mathrm{H}_{2} \mathrm{O}-1$, assim como o B. subtilis, se enquadra nestes quesitos e foi identificada como produtora de uma molécula lipopeptídica. Esta cepa foi inicialmente isolada a partir de um reservatório de petróleo brasileiro, localizado em águas profundas em uma plataforma do Rio de Janeiro ${ }^{81}$ e, recentemente, a molécula produzida por este micro-organismo foi caracterizada pelo Laboratório de Genética Microbiana da UFRJ como surfactina-like, por produzir surfactinas com as porções lipídicas $\mathrm{C}_{13}, \mathrm{C}_{14}$ e $\mathrm{C}_{15}$ e uma porção lipídica adicional de $\mathrm{C}_{16}$. Foi estudada pelas suas propriedades antimicrobianas $^{82,83}$ e agora é produzida e utilizada em estudos em andamento no Laboratório de Biotecnologia Microbiana da UFRJ. ${ }^{84}$

\section{Propriedades antimicrobianas dos biossurfactantes}

Uma ampla gama de biossurfactantes demonstrou atividade antimicrobiana contra bactérias, fungos filamentosos, leveduras, algas e vírus. ${ }^{3}$ Dentre eles, o ramnolipídio e surfactina já foram relatados possuindo esta atividade. ${ }^{85}$ Dentre os biossurfactantes, a classe dos lipopeptídeos é a mais relatada em termos de ação antimicrobiana. O gênero Bacillus é responsável pela produção dos lipopeptídeos surfactantes mais bem conhecidos.$^{85,86}$ Além da surfactina, este gênero também produz outros lipopeptídeos com as mesmas propriedades: fengicina, iturina, bacillomicinas e micosubtilinas. Outras espécies do gênero Bacillus, além do B. subtilis, são conhecidas como produtoras de biossurfactantes lipopeptídicos com ação antimicrobiana, como o B. licheniformis, produtor da lichenisina e o B. pumilus, produtor da pumilacidina. ${ }^{85}$ Recentemente, foi confirmada a atividade antimicrobiana sobre 29 bactérias pelo uso de dois lipopeptídeos de B. subtilis. ${ }^{86}$ Lipopeptídeos produzidos por B. subtilis e por B. licheniformis foram testados contra dois micro-organismos patogênicos, sendo o produto de $B$. subtilis efetivo contra o micro-organismo Gram-positivo e não efetivo contra o Gram-negativo e o inverso ocorreu para o produto de $B$. licheniformis. ${ }^{87}$ Este efeito antimicrobiano provavelmente foi mais eficiente no Gram-positivo do que no Gram-negativo devido às diferenças nas estruturas das paredes celulares, causando uma maior inibição do crescimento celular, pois em geral, os micro-organismos Gram-positivos possuem alta sensibilidade a detergentes aniônicos enquanto os Gram-negativos não. ${ }^{88} \mathrm{~A}$ surfactina interfere mais intensamente em membranas contendo fosfolipídios que possuem cadeias mais curtas e/ou estão em organização fluída, consequentemente interferindo em suas funções biológicas por meio da inserção nas bicamadas lipídicas, modificando a permeabilidade da membrana pela formação de canais iônicos ou por carrear cátions mono ou di-valentes e solubilizando a membrana por seu mecanismo detergente. ${ }^{89}$ Outras classes de biossurfactantes que são relatadas com ação antimicrobiana são os ramnolipídios de $P$. aeruginosa e os sophorolipídios de Candida bombicola. Os lipídeos de mannosileritritol (MEL-A e MEL-B) produzidos por uma linhagem de Candida antarctica exibiram ação antimicrobiana contra bactérias Gram-positivas. ${ }^{85} \mathrm{Em}$ um trabalho realizado recentemente pelo nosso grupo foi possível verificar que o ramnolipídio purificado apresenta propriedade antimicrobiana contra L. monocytogenes ATCC 19112 e ATCC 7644, inibindo em $100 \%$ o crescimento de ambas. Também foi confirmada a inibição do crescimento planctônico destas mesmas linhagens utilizando surfactina de $B$. subtilis LB5a produzida em manipueira como substrato..$^{90}$ A atividade antimicrobiana de uma mistura de sete homólogos de ramnolipídios produzida por P. aeruginosa AT10 sobre ampla gama de bactérias Gram-positivas e Gram-negativas, leveduras e fungos filamentosos foi avaliada e, devido às propriedades físico-químicas e elevada atividade antimicrobiana, este produto poderia ser visto como uma ferramenta útil em processos de biorremediação, cosméticos e aplicações em indústrias de alimentos ${ }^{67}$ As diferenças encontradas na literatura entre percentuais de inibição do crescimento e também de formação de biofilme entre o ramnolipídio bruto e o ramnolipídio purificado de $P$. aeruginosa, contra mesmos micro-organismos, provavelmente são devidas à presença de outros componentes (fatores de virulência e sinais de quorum sensing) no meio bruto que após a purificação são total ou parcialmente eliminados. Estes componentes podem ser alguns fatores de virulência de natureza proteica e ainda de quorum sensing: elastase, protease LasA, protease alcalina, fosfolipase C, lipase, exotoxina A, cianeto, piocianina, lectina e superóxido dismutase; que têm produção coordenada por quorum sensing e a mesma ocorre concomitantemente à produção de ramnolipídios por $P$. aeruginosa. ${ }^{91,92}$ As moléculas que possuem atividade quorum sensing produzidas por $P$. aeruginosa 
também podem interferir sobre o comportamento de outros micro-organismos que não produzem os mesmos sinais, um exemplo é o 3-oxo- $\mathrm{C}_{12}$-HSL (sistema LasI/R) e o PQS que apresentam excelentes propriedades antibacterianas. ${ }^{93}$

\section{Propriedades antibiofilmes dos biossurfactantes}

Estudos recentes mostraram que o pré-condicionamento de superfícies com biossurfactantes podem reduzir consideravelmente a contaminação microbiana de materiais e inibir ou diminuir a formação subsequente de biofilmes ${ }^{94}$ (Figura 1).

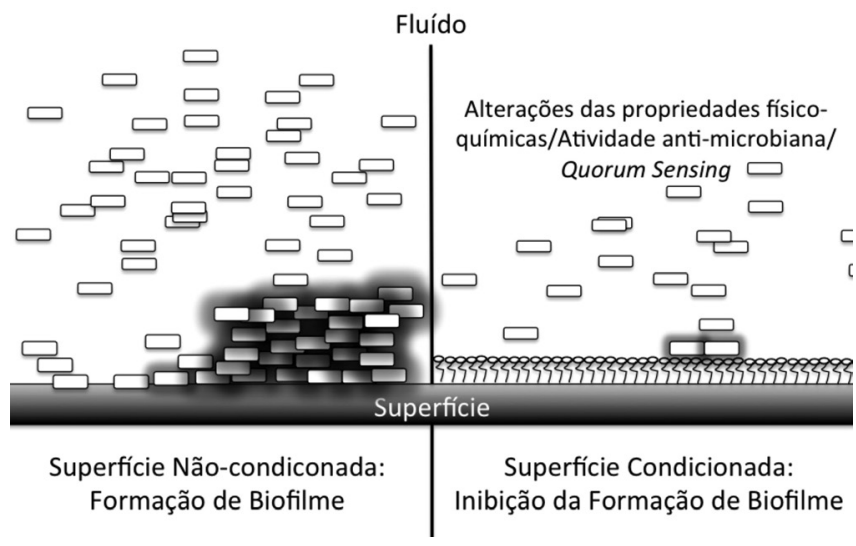

Figura 1. Efeito inibitório da formação de biofilmes através do condicionamento da superfície por biossurfactante

Quando um surfactante é adsorvido a superfícies hidrofóbicas, normalmente orienta o grupo hidrofóbico para a superfície e expõe o grupo polar à água. A superfície torna-se assim hidrofílica e, como resultado, a tensão interfacial entre a superfície e a água é reduzida. ${ }^{19}$ Os ramnolipídios atuam no mecanismo de dessorção das células presentes em biofilmes de $P$. aeruginosa ${ }^{95} \mathrm{O}$ pré-condicionamento de cateteres uretrais com surfactina inibiu totalmente a formação de biofilmes de $S$. enterica, E. coli e P. mirabilis. ${ }^{96}$ Um biossurfactante produzido por $P$. fluorescens (não caracterizado) utilizado no pré-condicionamento de superfícies de PTFE e aço inox 304 AISI demonstrou uma redução significativa da adesão de L. monocytogenes LO28 no aço inox em diferentes temperaturas (até $92 \%$ ); entretanto, não foi evidenciada uma redução na adesão em superfície de $\mathrm{PTFE}^{34}$. Superfícies de borracha de silicone condicionadas com ramnolipídios de $P$. aeruginosa, obtiveram inibições na adesão de 60,9 \%, 53,1\%, $58,2 \%$ e $33,8 \%$ contra as bactérias $R$. dentocariosa, S. epidermidis, $S$. salivarius e $S$. aureus, respectivamente, com solução de ramnolipídio não diluída (4 g/L) ${ }^{97}$ Os trabalhos realizados recentemente pelo nosso grupo demonstraram que o pré-condicionamento do aço inox 304 com surfactina $(0,1 \%)$ foi capaz de reduzir significativamente a adesão de L. monocytogenes ATCC $19112 \mathrm{em}$ aproximadamente $10^{2} \mathrm{UFC} / \mathrm{cm}^{2}$ e $10^{1} \mathrm{UFC} / \mathrm{cm}^{2}$ para E. sakazakii ATCC 29004. Já em polipropileno os resultados do condicionamento com surfactina 0,1 $\%$ demonstraram uma redução significativa no número de células aderidas de L. monocytogenes, E. sakasakii e S. enteritidis em aproximadamente $10^{1} \mathrm{UFC} / \mathrm{cm}^{2}{ }^{28} \mathrm{O}$ pré-condicionamento de superfícies de poliestireno com ramnolipídio bruto, ramnolipídio purificado e surfactina reduziram significativamente a adesão das cepas ATCC 19112, 19117, 15313 e 7644 de L. monocytogenes e foram mais eficientes que o dodecil-sulfato de sódio. ${ }^{90}$ Superfícies de poliestireno condicionadas por surfactina e por ramnolipídios avaliadas em diferentes temperaturas reduziram a adesão em todas as condições com a surfactina (Staphylococcus aureus, L. monocytogenes e Micrococcus luteus) e o ramnolipídio promoveu uma pequena redução na adesão de $S$. aureus. ${ }^{99}$ Estes dados reforçaram a ideia de que alguns biossurfactantes são efetivos na inibição da adesão de acordo com as características das superfícies. Foi comprovado que a B. kururiensis possui o sistema HSL de quorum sensing, chamado de BraI/R, que produz e responde ao 3-oxo- $\mathrm{C}_{12}$-HSL e é extremamente similar ao LasI/R de $P$. aeruginosa (nesta é interconectado com outros sistemas regulatórios e é o regulador global envolvido na regulação de muitos genes que possuem importância na virulência e colonização). ${ }^{100}$ Também foi relatada a existência de uma outra molécula produzida por $P$. aeruginosa que possui efeito antibiofilmes, o ácido graxo insaturado cis-2-decenóico, porém, seu mecanismo de ação ainda não foi elucidado. ${ }^{101}$ Desta forma a ação dos ramnolipídios pode ser otimizada pela presença destes compostos, ajudando a inibir a formação dos biofilmes. Os lipopeptídeos são capazes de modificar a hidrofobicidade da superfície bacteriana e consequentemente alterar a adesão destes micro-organismos a superfícies sólidas e seus efeitos dependem da hidrofobicidade bacteriana inicial, assim como do tipo de lipopeptídeo e sua concentração, podendo aumentar ou diminuir a hidrofobicidade da superfície bacteriana em função desta ser mais ou menos hidrofóbica. ${ }^{22}$ Do ponto de vista fisiológico, é possível que cada bactéria possua determinada resposta genética que permita que elas sobrevivam e ainda sejam bem sucedidas em condições de limitação de nutrientes e outros tipos de condições estressantes como o estresse osmótico, anóxia e mudanças de $\mathrm{pH}^{102}$. E por que não incluir nesta lista o estresse por agentes antimicrobianos ou por moléculas reguladoras de quorum sensing produzidas por outros micro-organismos? B. subtilis e outras espécies pertencentes ao mesmo gênero produzem moléculas sinalizadoras conhecidas como peptídeos autoindutores (AIP), que são peptídeos contendo de 5 a 34 aminoácidos com arquiteturas não usuais, os peptídeos triptofano isoprenilados. ${ }^{103}$ Estas moléculas também podem ter efeito sobre a formação de biofilmes. Recentemente foi identificada uma mistura de D-aminoácidos produzidos por $B$. subtilis que fazem com que as fibras proteicas amilóide-like presentes na matriz extracelular de biofilmes se separem das células, permitindo que estas escapem da matriz. Estes compostos também podem atuar em outros micro-organismos, prevenindo a formação de biofilmes. ${ }^{101}$ Outro fator que poderia interferir sobre a formação de biofilmes seria a presença de lactonases. Estas são produzidas pelo gênero Bacillus e são conhecidas como enzimas AHL-hidrolases, as mesmas são quorum-quenchers, ou seja, interferem na sinalização do quorum-sensing impedindo eventos de sinalização dependentes de densidade celular tanto de espécies Grampositivas quanto de espécies Gram-negativas. ${ }^{27,104}$ Um lipopeptídio produzido por $B$. circulans foi utilizado no pré-condicionamento de superfícies de poliestireno contra diversos micro-organismos patogênicos e as porcentagens de inibição variaram de 15 a $89 \% .{ }^{105} \mathrm{Um}$ extrato contendo surfactina, utilizado como agente condicionante de superfícies de poliestireno, inibiu aproximadamente $42 \%$ a formação de biofilmes de L. monocytogenes ATCC $19112 .{ }^{106}$ Com todas essas propriedades, estes compostos poderiam ser utilizados para evitar a contaminação de alimentos diretamente, como aditivo (pelo uso de formulações adequadas), aumentando a vida de prateleira do produto sem preocupação com a saúde dos consumidores, deixando de lado a necessidade de adicionar conservantes sintéticos, que na maioria dos casos, são perigosos para a saúde; ou indiretamente, como formulações detergentes para limpar as superfícies às quais os alimentos entram em contato. ${ }^{61} \mathrm{O}$ efeito antiadesivo ou inibitório dos biossurfactantes adsorvidos às superfícies pode estar ligado a alterações singulares nas propriedades físico-químicas, alterando as interações atrativas entre a superfície e o micro-organismo, combinado ou não com um efeito de dessorção deste biocomposto, ${ }^{65,90,98}$ e/ou ainda que os biossurfactantes ou outros compostos que tenham sido produzidos por estes micro-organismos podem estar atuando como fatores quorum 
sensing,$^{29}$ interferindo positivamente ou negativamente no processo de adesão e formação de biofilmes, o que justificaria as diferenças encontradas nos resultados de diferentes linhagens/espécies em diferentes superfícies. Além disso, este efeito inibitório poderia ser potencializado por uma ação antimicrobiana dos biossurfactantes. Diferenças que possam ser encontradas nos percentuais de formação de biofilmes de mesmas linhagens de micro-organismos quando as mesmas superfícies forem tratadas com os ramnolipídios ou com as surfactinas, por exemplo, podem ocorrer devido às diferenças químicas encontradas nas misturas dos homólogos produzidos nas fermentações. Esse fato pode dificultar a comparação de percentuais encontrados na literatura e, portanto, é essencial que os trabalhos apresentem a composição da mistura de homólogos juntamente com os ensaios de atividade antibiofilme ou atividade antimicrobiana. $\mathrm{O}$ condicionamento de superfícies de poliestireno com ramnolipídio e com surfactina reduziu a adesão de L. monocytogenes ATCC 19112 em 17 e $60 \%$, respectivamente. ${ }^{65}$ Já em outro trabalho esta mesma cepa teve sua adesão inibida em $53 \%$ para ambos. ${ }^{90}$ A diferença observada no valor de inibição da adesão encontrados entre estes dois trabalhos para o ramnolipídio provavelmente se deve a possíveis diferenças nos constituintes do meio de cultivo como fatores de virulência, pois foram obtidos em diferentes fermentações, enquanto a surfactina utilizada foi a mesma. ${ }^{65,90}$

\section{Atividade anticorrosiva}

$\mathrm{O}$ aço inox é um material frequentemente utilizado devido a sua alta resistência à corrosão. Em contato com o ar, a superfície é rapidamente coberta por uma camada de Óxido de Cromo e óxido de Ferro, o que aumenta sua resistência à corrosão, a qualidade deste filme formado depende das condições ambientais e principalmente do conteúdo de Cromo da liga metálica. Para aumentar a resistência a corrosão, o condicionamento de superfícies pode ser aplicado, reduzindo a formação de Óxido de Ferro e aumentando a formação de Óxido e Hidróxido de Cromo, sugerindo a existência de propriedades protetoras dos biossurfactantes contra a corrosão ${ }^{107}$ (Figura 2).

\section{AR}

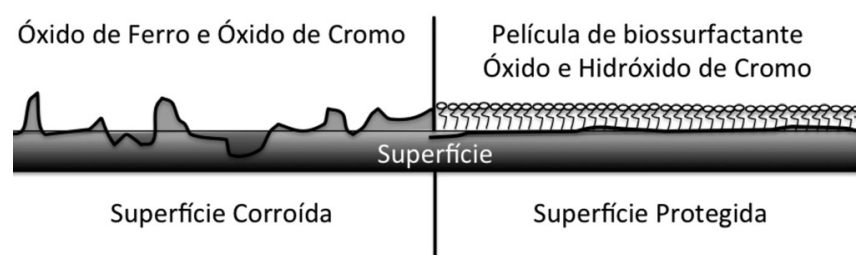

Figura 2. Efeito inibitório da corrosão através do condicionamento da superficie por biossurfactante

Foi verificado um aumento na razão $\mathrm{Cr} / \mathrm{Fe}$ saindo de 0,9 na superfície limpa (não condicionada) para 1,4 na superfície condicionada, sugerindo a existência de propriedades anticorrosivas dos biossurfactantes e os mesmos tornaram as superfícies mais hidrofílicas. ${ }^{31} \mathrm{O}$ aço inox AISI 304 possui conteúdo de Cromo equivalente a $18 \%$ e por isso, possui uma resistência relativamente fraca à corrosão. ${ }^{107} \mathrm{O}$ processo de corrosão metálica resulta na formação de produtos de corrosão e na liberação de energia, ou seja, as superfícies mais protegidas contra a corrosão serão as que apresentam valores mais baixos de energia livre de superfície total. Pela interação com íons $\mathrm{H}^{+}$, a superfície tende a ficar mais hidrofílica, o que pode ser o indício da ocorrência de um processo corrosivo, porém, no caso dos condicionamentos por biossurfactantes a hidrofilicidade pode estar associada a formação de uma película destas moléculas sobre a superfície orientando a cabeça hidrofílica para o meio e a cauda hidrofóbica para a superfície mantendo a mesma protegida da interação com íons $\mathrm{H}^{+} \mathrm{e} \mathrm{O}_{2}$, evitando a corrosão. Existe um grande potencial de uso dos biossurfactantes como agentes condicionantes de superfícies para reduzir a formação de biofilmes de micro-organismos comumente encontrados em ambientes industriais. Alguns estudos relativamente recentes mostraram que superfícies pré-condicionadas com biossurfactantes são capazes de reduzir significativamente a contaminação microbiana e inibir ou reduzir o desenvolvimento subsequente de biofilmes. ${ }^{31}$ Além disso, alguns destes produtos, como os ramnolipídios, podem ser utilizados como agentes protetores de superfícies metálicas contra corrosão, pois foi confirmado que a presença de biossurfactante de $P$. fluorescens em aço inox 304 postergou a corrosão desta superfície. ${ }^{107}$

\section{CONCLUSÕES}

$\mathrm{Na}$ indústria de alimentos, diversos estudos detalhados sobre a utilidade dos biossurfactantes como agentes inibidores da adesão de micro-organismos e, consequentemente, da inibição da formação de biofilmes, têm sido realizados, cujos resultados nos permitem afirmar que futuramente eles poderão ser utilizados e produzidos em larga escala, suprindo a necessidade do uso de produtos sintéticos, ou diminuindo as concentrações de produtos sintéticos que são utilizadas atualmente. Os biossurfactantes podem também ser utilizados como agentes inibidores da corrosão, um problema comum. Assim seu campo de aplicação poderia ser ampliado, podendo atuar simultaneamente como agente antimicrobiano, antibiofilme e ainda anticorrosivo. Desta forma pode-se direcionar os tipos de biossurfactantes para cada determinada aplicação, assim como para aplicações com múltiplas finalidades. O grande potencial de aplicação destes produtos diretamente nas indústrias alimentícias, como forma de prevenção da formação de biofilmes por diferentes micro-organismos, em superfícies com as quais os alimentos entram em contato durante o processamento, pode beneficiar diretamente o consumidor, que terá a possibilidade de ter em suas mesas uma maior garantia de qualidade microbiológica de seus alimentos. Ainda como vantagem em potencial destes produtos estaria a substituição ou redução da quantidade utilizada de produtos sintéticos não biodegradáveis ou pouco biodegradáveis por produtos de origem natural, obtidos por meio do cultivo de micro-organismos em substratos renováveis. As indústrias teriam uma potencial redução de custos com o tratamento de resíduos, que seriam mais facilmente degradados devido a ausência/redução de produtos pouco biodegradáveis no efluente final, os quais geralmente dificultam o tratamento. Outro fator responsável pela redução de custos seria a necessidade de concentrações muito inferiores de biossurfactante em relação ao surfactante convencional para atingir os resultados esperados. Ademais, os próprios resíduos da indústria alimentícia possuem potencial para serem utilizados como substrato para a produção dos biossurfactantes.

\section{REFERÊNCIAS}

1. Maukonen, J.; Mättö, J.; Wirtanen, G.; Raaska, T.; Mattila-Sandholm, T.; Saarela, M.; J. Ind. Microbiol. Biotechnol. 2003, 30, 327.

2. Bagge-Ravn, D.; Yin, N.; Hjelm, M.; Christiansen, J. N.; Johansen, C.; Gram, L.; Int. J. Food Microbiol. 2003, 87, 239.

3. Nitschke, M.; Costa, S. G. V. A. O.; Trends Food Sci. Technol. 2007, 18, 252.

4. http://cenormagill.com.br/artigos/Biofilmes\%20Microbianos.pdf, acessada em Abril 2013.

5. Lindsay, D.; Holy, A. von.; Food Microbiol. 1997, 4, 383.

6. Jenkinson, H. F.; Lappin-Scott, H. M.; Trends Microbiol. 2001, 9, 9.

7. http://www.milknet.com.br/?pg=artigos_tecnicos\&id=7\&local=1, acessada em Abril 2013. 
8. Kim, H.; Ryu, J. H.; Beuchat, L. R.; Appl. Environ. Microbiol. 2006, 72, 5846.

9. Chavant, P.; Martinie, B.; Meylheuc, T.; Bellon-Fontaine, M. N.; Hebraud, M.; Appl. Environ. Microbiol. 2002, 68, 728.

10. Hood, S. K.; Zottola, E. A.; Food control. 1995, 6, 9.

11. Kalmokoff, M. L.; Austin, J. W.; Wan, X. D.; Sanders, G.; Banerjee, S.; Farber, J. M.; J. Appl. Microbiol. 2001, 91, 725.

12. Takhistov, P.; George, B.; Bioprocess Biosys. Eng. 2004, 26, 259.

13. Parizzi, S. Q. F.; Andrade, N. J. De; Silva, C. A. De S.; Soares, N. F. F.; Silva, E. A. M. da.; Braz. Arch. Biol. Technol. 2004, 47, 77.

14. Wong, A. C. L.; J Dairy Sci. 1998, 81, 2765.

15. Chae, M. S.; Schraft, H.; Hansen, L. T.; Mackereth, R.; Food Microbiol. 2006, 23, 250.

16. Bellon-Fontaine, M. N.; Rault, J.; Van Oss, C. J.; Colloids Surf. B. 1996 7, 47.

17. Busscher, H. J.; Weeerkamp, A. H.; Van Der Mei, H. C.; Van Pelt, A. W J.; De Jong, H. P.; Arends, J.; Appl. Environ. Microbiol. 1984, 48, 980.

18. Carpentier, B.; Cerf, O.; J. Appl. Bacteriol. 1993, 75, 499.

19. Machado, S. M. de O.; Tese de Mestrado, Universidade do Minho, Braga, Portugal, 2005.

20. Djordjevic, D.; Wiedmann, M.; Mclandsborough, L. A.; Appl. Environ. Microbiol. 2002, 68, 2950.

21. Simões, M.; Simões, L.; Vieira, M. J.; LTW - Food Sci. Technol. 2010 , 43, 573.

22. Ahimou, F.; Jacques, P.; Deleu, M.; Enzyme Microb. Technol. 2000, 27, 749.

23. Sommer, P.; Martin-Rouas, C.; Mettler, E.; J. Food Microbiol. 1999, 16 , 503.

24. Hamadi, F.; Latrache, H.; Colloids Surf. B. 2008, 65, 134.

25. Van Oss, C. J.; Colloids Surf. B. 1995, 5, 91.

26. Sotirova, A.V.; Spasova, D. I.; Galabova, D. N.; Karpenko, E.; Shulga, A.; Cur. Microbiol. 2008, 56, 639.

27. Parsek, M. R.; Greenberg, E. P.; Trends Microbiol. 2005, 13, 27.

28. Kolter, R.; Greenberg, E. P.; Nature. 2006, 441, 300.

29. Yarwood, J. M.; Bartels, D. J.; Volper, E. M.; Greenberg, E. P.; J. Bacteriol. 2004, 186, 1838.

30. Ly, M. H.; Vo, N. H.; Le, T. M.; Belin, J.-M.; Waché, Y.; Colloids Surf. B. 2006, 52, 149 .

31. Meylheuc, T.; Methivier, C.; Renault, M.; Herry, J.-M.; Pradier, C.-M.; Bellon-Fontaine, M. N.; Colloids Surf. B. 2006b, 52, 128.

32. Borucki, M. K.; Peppin, J. D.; White, D.; Loge, F.; Call, D. R.; Appl. Environ Microbiol. 2003, 69, 7336.

33. Chae, M. S.; Schraft, H.; Int. J. Food Microbiol. 2000, 62, 103.

34. Meylheuc, T.; Van Oss, C. J.; Bellon-Fontaine, M. N.; J. Appl. Microbiol. 2001, 91,822 .

35. Arizcun, C.; Vasseur, C.; Labadie, J. C.; J. Food Prot. 1998, 61, 731.

36. Hirsh, D. C.; Zee, Y. C.; Microbiologia Veterinária, Guanabara Koogan: Rio de Janeiro, 2003.

37. Germano, P. M. L.; Germano, M. I. S.; Higiene e vigilância sanitária de alimentos, Varella: São Paulo, 2003.

38. Jay, J. M.; Microbiologia de alimentos, Artmed: Porto Alegre, 2005.

39. Costa, A. C. M.; Araujo, L. V.; Lins, U. G. C.; Freire, D. M .G., Garcia, M. E.; Borges, C. P. Desalination. submetido.

40. Hinsa, S. M.; Espinosa-Urgel, M.; Ramos, J. L.; O’toole, G. A.; Mol. Microbiol. 2003, 49, 905.

41. Stepanovic, S.; Vukovic, D.; Dakic, I.; Savic, B.; Svabic-Vlahovic, M. J. Microbiol. Methods. 2000, 40, 175 .

42. Gomes, F. I.; Teixeira, P.; Azeredo, J.; Oliveira, R.; Cur. Microbiol. 2009, $59,118$.

43. Rodrigues, D.; Teixeira, P.; Oliveira, R.; Azeredo, J.; J. Food Protec. 2011, 74, 32

44. Sousa, C.; Teixeira, P.; Oliveira, R.; J. Basic Microbiol. 2009, 49, 363.
45. Stepanovic, S.; Cirkovic, I.; Ranin, L.; Svabic-Vlahovic, M.; Lett. Appl. Microbiol. 2004, 38, 428.

46. Simões, M.; Pereira, M. O.; Sillankorva, S.; Azeredo, J.; Vieira, M. J.; Biofouling. 2007, 23, 249.

47. Somers, E. B.; Wong, A. C. L.; J. Food Protec. 2004, 67, 2218.

48. Stopforth, J. D.; Samelis, J.; Sofos, J. N.; Kendall, P. A.; Smith, G. C. J. Food Protec. 2002, 65, 1717

49. http://www.bndes.gov.br, acessada em Março 2009.

50. Wunsch, J. R.; Polystyrene - Synthesis, Production and Applications. RAPRA: Reino Unido, 2000.

51. Nitschke, M.; Pastore, G. M. Rev. Biotecnol. Ciência Desenv. 2003, 31, 63.

52. Desai, J. D.; Banat, I. M.; Microbiol. Mol. Biol. Rev. 1997, 61, 47.

53. Fiechter, A.; Tibtech. 1992, 10, 1

54. Nitschke, M.; Pastore, G. M.; Quím. Nova. 2002, 25, 772.

55. Banat, I. M; Makkar, R. S.; Cameotra, S. S.; Appl. Microbiol. Biotechnol. 2000, 53, 495.

56. Cooper, D. G.; Microbiol. Sci. 1986, 3, 145.

57. Parkinson, M.; Biotechnol. Adv. 1985, 3, 65.

58. Wang, S.Y.; Vipulanandan, C. University of Houston CIGMAT Department of Civil and Environmental Engineering, 1-2, 1998.

59. Mulligan, C. N.; Environ. Pollut. 2005, 133, 183.

60. Singh, P.; Cameotra, S. S. Trends Biotechnol. 2004, 22, 142.

61. Freire, D. M. G.; Araujo, L. V.; Kronemberger, F. A.; Nitschke, M. Em Innovation in Food Engineering: New Techniques and Products; PASSOS, M. L.; RIBEIRO, C. P., eds.; Taylor \& Francis Group: Boca Raton, 2009, 685-705.

62. Rosenberg, E.; Ron, E. Z.; Appl. Microbiol. Biotechnol. 1999, 52, 154.

63. Pires, R. C.; Araujo, L. V.; Ferreira, F. S.; Siqueira, R. S. De; Nitschke, M.; III Congresso Latino-americano de Higienistas de Alimentos, IX Congresso Brasileiro de Higienistas de Alimentos, Porto Seguro, Brasil, 2007.

64. Ferreira, F. S.; Pires, R. C.; Araujo, L. V.; Siqueira, R. S. de; Nitschke, M. VII Simpósio Latino Americano de Ciências de Alimentos, Campinas, Brasil, 2007.

65. Araujo, L. V.; Pires, R. C.; Siqueira, R. S. De; Freire, D. M. G.; Nitschke, M. II International Conference on Environmental, Industrial and Applied Microbiology (BioMicroWorld 2007), Sevilla, Espanha, 2007.

66. Reis, R. S. Tese de Mestrado, Universidade Federal do Rio de Janeiro, Rio de Janeiro, Brasil, 2008.

67. Abalos, A.; Pinazo, A.; Infante, M. R.; Casals, M.; Garcia, F.; Manresa, A.; Langmuir. 2001, 17, 1367.

68. Santos, A. S.; Sampaio, A. P. W.; Vasquez, P. S.; Santa Anna, L. M.; Pereira Jr, N.; Freire, D. M. G.; Appl. Biochem. Biotechnol. 2002, 98 , 1025.

69. Santa Anna, L. M.; Sebastian, G. V.; Santos, A. S.; Alves, T. M.; Menezes, E. P.; Perreira, Jr. N.; Freire, D. M. G.; Braz. J. Chem. Eng. 2002, $19,159$.

70. Santa Anna, L. M.; Freire, D. M. G.; Borges, C. P.; Kronemberger, F. A.; Pereira, Jr. N.; Petróleo Brasileiro S.A. Br PI 0.405.952-2, 2004.

71. Kronemberger, F. A.; Anna, L. M. M. S.; Fernandes, A. C. L. B.; Menezes, R. R.; Borges, C. P.; Freire, D. M. G.; Appl. Biochem. Biotechnol. 2008, 147, 33 .

72. Kronemberger, F. A.; Santa Anna, L. M.; Tavares, L. F. D.; Fernandes, A. C. L. B.; Borges, C. P. Freire, D. M. G.; Menezes, R. R. XVI Simpósio Nacional de Bioprocessos, Curitiba, Brasil, 2007.

73. Santa Anna, L. M. Tese de Doutorado, Universidade Federal do Rio de Janeiro, Rio de Janeiro, Brasil, 2005.

74. Santa Anna, L. M.; Soriano, A. U.; Gomes, A. C. ; Menezes, E. P.; Gutarra, M.; Freire, D. M. G.; Perreira, Jr. N.; J. Chem. Technol. Biotechnol. 2007, 82, 687.

75. Tavares, L.F.D. Tese de Doutorado, Universidade Federal do Rio de Janeiro, Rio de Janeiro, Brasil, 2012. 
76. Zhang, H; Hanada, S; Shigematsu, T.; Shibuya, K.; Kamagata,Y.; Kanagawa, T.; Kurane, R.; Int. J. Syst. Evol. Microbiol. 2000, 50, 743.

77. Cooper, D. G.; Goldenberg, B. G.; Appl. Environ. Microbiol. 1987, 53, 224.

78. Nitschke, M. Tese de Doutorado, Universidade Estadual de Campinas, São Paulo, Brasil, 2004.

79. Yakimov, M. M.; Timmis, K. N., Wray, V.; Fredrickson, H. L. Appl. Environ. Microbiol. 1995, 61, 1706.

80. Youssef, N. H.; Duncan, K. E.; Mcierney, M. J.; Appl. Environ. Microbiol. 2005, 71, 7690 .

81. Sebastián, G. V. Tese de Mestrado, Universidade Federal do Rio de Janeiro, Rio de Janeiro Brasil, 1999.

82. Korenblum, E.; Sebastián, G. V.; Paiva, M. M.; Coutinho, C. M. L. M.; Magalhães, F. C. M.; Peyton, B. M.; Seldin, L.; Appl. Microbial Cell Physiol. 2008, 79, 97.

83. Korenblum, E.; Weid, I. Von Der; Santos, A. L. S.; Rosado, A. S.; Sebastián, G. V.; Coutinho, C. M. L. M.; Magalhães, F. C. M.; Paiva, M. M. De; Seldin, L.; J. Appl. Microbiol. 2005, 98, 667.

84. Korenblum, E.; Araujo, L. V.; Guimarães, C. R.; Souza, L. M.; Sassaki, G.; Abreu, F.; Nitschke, M.; Lins, U.; Freire, D. M. G.; Barreto-Bertger, E.; Seldin, L.; BMC Microbiol. 2012, 12, 252.

85. Das, P.; Mukherjee, S.; Sen, R.; J. Appl. Microbiol. 2008, 104, 1675.

86. Fernandes, P. A. V.; Arruda, I. R. De; Santos, A. F. A. B. Dos; Araújo, A. A. De; Maior, A. N. S.; Ximenes, E. A.; Braz. J. Microbiol. 2007, 38, 704.

87. Rivardo, F.; Turner, R. J.; Allegrone, G.; Ceri, H.; Martinotti, M. G.; Appl. Microbiol. Biotechnol. 2009, 83, 541

88. Tortora, G. J.; Funke, B. R.; Case, C. L. Microbiologia. Artmed: Porto Alegre, 2005.

89. Bouffioux, O.; Berquand, A.; Eeman, M.; Paquot, M.; Dufrêne, Y. F.; Brasseur, R.; Deleu, M.; Biochim. Biophys. Acta. 2007, 1768, 1758.

90. Araujo, L. V.; Abreu, F.; Lins, U.; Santa Anna, L. M. M.; Nitschke, M.; Freire, D. M. G.; Food Res. Int. 2011, 44, 481.
91. Dong, Y. H.; Zhang, X. F.; Xu, J. L.; Tan, A. T.; Zhang, L. H.; Mol. Microbiol. 2005, 58, 552 .

92. González, J. E. \& Keshavan, N. D.; Microbiol. Mol. Biol. Rev. 2006, 70, 859.

93. Williams, P. \& Cámara, M.; Cur. Opin. Microbiol. 2009, 12, 1.

94. Meylheuc, T.; Renault, M.; Bellon-Fontaine, M. N. Int. J. Food Microbiol. 2006a, 109, 71

95. Boles, B. R.; Thoendel, M.; Singh, P. K.; Mol. Microbiol. 2005, 57 , 1210

96. Mirelles II, J. R.; Toguchi, A.; Harshey, R. M.; J. Bacteriol. 2001, 183, 5848 .

97. Rodrigues, L. R.; Banat, I. M.; Van Der Mei, H. C.; Teixeira, J. A.; Oliveira, R.; J. Appl. Microbiol. 2006, 100, 470.

98. Nitschke, M; Araujo, L.V., Costa, S. G. V. A. O. ; Pires, R. C.; Zeraik, A. E.; Fernandes, A. C. L. B.; Contiero, J.; Lett. Appl. Microbiol. 2009, $49,241$.

99. Zeraik, A. N. \& Nitschke, M.; Curr. Microbiol. 2010, 61, 554.

100. Suárez-Moreno, Z. R.; Caballero-Mellado, J.; Venturi, V.; Microbiol. 2008, 154, 2048.

101. Shank, E. A.; Kolter, R.; Cur. Opin. Microbiol. 2011, 14, 741

102. Kjelleberg, S.; Molin, S.; Cur. Opin. Microbiol. 2002, 5, 254.

103. Williams, P.; Winzer, K.; Chan, W. C.; Cámara, M. Philos. Trans. Royal Soc. B. 2007, 362, 1119.

104. Kauffman, G. F.; Sartorio, R.; Lee, S. H.; Rogers, C. J.; Meijler, M. M.; Moss, J. A.; Clapham, B.; Brogan, A. P.; Dickerson, T. J.; Janda, K. D.; Proc. Nati. Acad. Sci. 2005, 102, 309.

105. Das, P.; Mukherjee, S.; Sen, R.; Colloids Surf. B. 2009, 71, 183.

106. Gomes, M. Z. do V.; Nitschke, M.; Food Control. 2012, 25, 441

107. Dagbert, C.; Meylheuc, T.; Bellon-Fontaine, M.-N.; Electrochim. Acta. 2006, 51,5221 . 